\title{
A Problematic Proxy? On Meisenberg, Rindermann, Patel and Woodley (2012). Analysis of the Relationship between Religiosity and Intelligence within Countries
}

\author{
Edward Dutton ${ }^{1}$ \\ Adjunct Professor of Anthropology of Religion, Oulu University, Oulu, Finland
}

This brief report is a commentary on Meisenberg, G., Rindermann, H., Patel, H., \& Woodley, M. (2012). Is it smart to believe in God? The relationship of religiosity with education and intelligence. Temas em Psicologia, 20(1), 101-120.

Meisenberg et al. (2012) are to be thanked for providing a long overdue analysis of the relationship between intelligence and religiosity within a large sample of countries. Drawing upon the World Values Survey between 1981 and $2009(N=345.743)$ across 96 countries they find that overall intelligence is negatively correlated with religious belief (70 countries), though there are exceptions ( 25 countries where it is positively correlated and 1 with no correlation). This is a clear, well-argued and meticulous piece of research and those interested in the relationship between religion and intelligence are surely in Meisenberg et al's (2012) debt. However, there are number of small issues in their article which I felt might be open to a slightly different interpretation from that which they suggest, or at least open to a parallel interpretation.

Firstly, they note that in countries with a very low average IQ (in sub-Saharan Africa), religiosity positively correlates with intelligence. They suggest that this is because, in such societies, religion is a system of explanation meaning that the more intelligent will be more religious because they can comprehend a more complex explanation. I think a more obvious explanation is that in such countries those with low intelligence are more likely to adhere to what might be regarded as 'superstition' rather than 'religion.' If researchers attempted to discern the extent to which the 'superstitious' and 'religious' were fervent and perceived a hidden hand behind events (a reasonable operational definition of religion, see Boyer, 2001) sub-Saharan Africa may well end up with an inverse relationship between intelligence and religiousness. Indeed, Meisenberg et al. concede that small scale societies do not employ "elaborated religion" (2012, p. 15).

Moreover, Meisenberg et al. (2012) used 'education' as a proxy for intelligence in reaching their correlations. This is slightly problematic because educational success only correlates with intelligence at .5 (e.g., Jensen, 1980, p. 316). The personality characteristics Conscientiousness, Neuroticism, Agreeableness and Openness-Intellect are positively correlated with educational success. However, they are also all positively associated with either religiosity per se (Conscientiousness and Agreeableness) or certain forms of it (Neuroticism with extrinsic religiosity and religious quest, and OpennessIntellect with liberal religiosity) (e.g., Saroglou, 2002 or Feist 1998). As such, it is perfectly possible that intelligence does predict relative religiosity, even if only weakly, within Sub-Saharan African countries.

Secondly, they found that in a number of countries, such as Sweden and Britain, being 'religious' is positively correlated with education. They put this down to the highly intelligent

Endereço para correspondência: Oulu University, Pentti Kaiteran katu 1, 90570 Oulu, Finland. E-mail: edward. dutton@oulu.fi 
rationalizing their own desire to be religious and arguing that there are two separate realms, somehow permitting them to identify as rational and concomitantly obtain the benefits of religion. They argue that this is congruous with research indicating that physical scientists are more religious than social scientists (e.g., Gross \& Simmons, 2009), though it might be noted that Ecklund and Scheitle (2007) found the opposite with sample of scholars from only the most elite US institutions. But this supposed 'separating of realms,' a rationally justified religion in itself, sounds very much like liberal religiosity (which, at its extremes, some might legitimately call atheism whatever adherents call it) which is, anyway, associated with relatively high intelligence (see Argyle, 1958 or Kanazawa, 2010), though not as high as the intelligence associated with atheism. It might be argued that in countries with strong welfare states it may even be that it is more stressful to be in a high status profession than in a low status one, which would promote high religiosity amongst those of high status. However, a survey of the studies indicates that this is not the case. Those of low status are more stressed (e.g. Berry \& Ataca, 2010, p. 644). As such, the simplest explanation for their finding is that education is an imperfect proxy for intelligence and that the same personality factors which predict educational success predict religiosity. In addition, Meisenberg et al's (2012) datasets do not appear to clearly distinguish between, for example, having a degree and having a doctorate. Thus, broadly, in certain countries, education may positively correlate with religiosity due to a failure to distinguish between different levels of higher education.

Thirdly, they noted that in South Korea, Buddhists have the lowest education, followed by Catholics and followed by Protestants (who are regarded as the most religious). But, again, education is an imperfect proxy for intelligence. They explain the difference by arguing that Protestantism is attractive to the highly educated because, with its internally consistent system of dogmatic teachings, it is rather like science. Indeed, they hypothesize that religions with a 'positive attitude to critical thinking' will be more attractive to the educated. This may be so, but, as already emphasized, education is an imperfect proxy for intelligence. So, the simplest explanation is that Protestantism provides more order and structure. This is attractive to people of high Conscientiousness and Conscientiousness strongly predicts years of education. And in addition, as Meisenberg et al. (2012) rightly point out, the educated are likely to be higher in Openness-Intellect and Protestantism is relatively new to South Korea and originally flourished, in the nineteenth century, amongst the more educated, also partly explaining the relationship (see $\mathrm{Yu}, 2002)$.

Finally, they observe that amongst the Mormons education positively correlates with religiosity (see Albrecht \& Heaton, 1984; Charlton, 2012; Merrill, Lyon, \& Jensen, 2003; Stark, 2005). However, they point out that the most intelligent Mormons are likely, every generation, to leave such a religion, explaining the positive relationship. If Mormons are more educated than the general population then, as discussed, personality factors may to be behind this rather than intelligence per se.

I hope these suggestions move the debate on but I should emphasize that they are, of course, relatively minor. Meisenberg et al. (2012) is an extremely useful article for Religious Studies scholars and deserves to be widely read.

\section{References}

Albrecht, S. L., \& Heaton, T. B. (1984). Secularization, higher education and religiosity. Review of Religious Research, 26, 43-58.

Argyle, M. (1958). Religious behaviour. London: Routledge.

Berry, J. W., \& Ataca, B. (2010). Culture factors in stress. In G. Fink (Ed.), Stress consequences: Mental, neurological and socioeconomic. New York: Academic Press.

Boyer, P. (2001). Religion explained: The human instincts that fashion gods, spirits and ancestors. London: William Heinnemann.

Charlton, B. (2012, September 7). British Mormon fertility and its determinants. In Mormon Fertility. Retrieved from http://mormonfertility. blogspot.co.uk/ 
Ecklund, E., \& Scheitle, C. (2007). Religion among academic scientists: Distinctions, disciplines and demographics. Social Problems, 54(2), 289-307.

Feist, G. J. (1998). A meta-analysis of personality in scientific and artistic creativity. Personality and Social Psychology Review, 2, 290-309.

Gross, N., \& Simmons, S. (2009). The religiosity of American college and university professors. Sociology of Religion, 70, 101-129.

Jensen, A. R. (1980). Bias in Mental Testing. New York: Free Press.

Kanazawa, S. (2010). Why liberals and atheists are more intelligent. Social Psychology Quarterly, 73(1), 33-57.

Meisenberg, G., Rindermann, H., Patel, H., \& Woodley, M. (2012). Is it smart to believe in God? The relationship of religiosity with education and intelligence. Temas em Psicologia, 20(1), 101-120.

Merrill, R. M., Lyon, J. L., \& Jensen, W. J. (2003). Lack of secularizing influence of education on religious activity and parity among Mormons. Journal for the Scientific Study of Religion, 42, 113-124.
Saroglou, V. (2002). Religion and the Five Factors of Personality: A meta-analytic review. Personality and Individual Differences, 32, 15-35.

Stark, R. (2005). The rise of Mormonism. New York: Columbia University Press.

Yu, C.-S. (2002). The relationship between Korean Catholics and Korean Protestants in the Early Mission Period. In C.-S. Yu (Ed.), Korea and Christianity. Fremont, CA: Asian Humanities Press. 